\title{
UNIVERSAL TRANSVERSE MERCATOR GRIDS FOR RECORDING COLLECTING SITES*
}

F.J.H. FREDEEN, Agriculture Canada, Research Station, 107 Science Crescent, Saskatoon, Saskatchewan. S7N OX2

Labels for biological, archaeological or other scientific specimens commonly indicate site locations either by estimating degrees, minutes and seconds, north and west, or, in settled areas by naming the nearest town, legal land survey designation or even a milepost on a highway, e.g. mile 145 on the Hansen Lake Road.

There are obvious problems with such designations. Degrees, minutes and seconds north latitude may be estimated simply enough with a romer or appropriate graduated rule. However, estimating distance west longitude by this method is difficult because lines of longitude converge by approximately $2 \mathrm{~km}$ for each degree northward at mid latitudes, requiring use of different scales as one moves north or south. Furthermore, scales in units of 60 are more difficult to construct than the decimal (metric) scale employed by Universal Transverse Mercator Grids.

The folly of expecting the nearest village, survey marker or highway to provide a permanent reference point is obvious. In time, many of these vanish. For instance, in a $25,000 \mathrm{~km}^{2}$ area of Saskatchewan extending south and west from Swift Current to provincial boundaries, a map of 1954 shows 96 names of towns, villages, etc. Only 30 of these are shown on the 1984 provincial highway map - a loss of about $70 \%$ in 30 years. Obviously we require a method for designating sites that will remain accurate for all time and yet is simple to use.

Contribution 874
Two main problems with using the above methods are that they are neither precise enough, nor do their data lend themselves to computer storage and retrieval. For example, on a small label for a pinned insect, one should, with brief designations be precise enough to distinguish between collecting sites not more than $100 \mathrm{~m}$ apart, if that is the distance separating upland and lowland areas, or neighboring streams flowing into or out of a small lake. In either instance, these represent significant habitat differences that future collectors may wish to locate on topographic maps.

A simple but refined method available today is the Universal Transverse Mercator (U.T.M.) Grid. It is so named because it is based upon the earth's surface being divided into north-south strip's rather than east-west as in Standard Mercator projections.

Dr. Roger Crosskey, British Museum (Natural History), London, England, during a recent visit to the Agriculture Canada Research Station in Saskatoon, reported that in Great Britain the U.T.M. system is now generally accepted for recording collection sites. The method also is fast becoming standard in Continental Europe. Collection data are computer stored in the British Biological Records Centre in the Institute of Terrestrial Ecology, Cambridge; as a result distribution maps of various taxa can be reproduced with relatively little effort. Dr. Crosskey expressed surprise that apparently no one in North America was using the system yet. In the 1960's, Cana- 
The easting and northing of the southwest corner of a map constitute the file name. The names of adjoining maps can be found by adding or subtracting $10000 \mathrm{~m}$ to easting and/or northing. Map requests should specify the appropriate easting and northing.

On this map the location of the $x$ in the sample grid is determined:

1) to the nearest $1000 \mathrm{~m}$ as 4 east and 6 north,

(2) to the nearest $100 \mathrm{~m}$ as 44 east and 63 north,

3) to the nearest $10 \mathrm{~m}$ as 434 east and 631 north.

In order to determine the location of this point in the overall UTM grid system, these eastings and northings are included in the map name:

e.g. to the nearest $100 \mathrm{~m}$ :

$12574400 \quad 5496300$

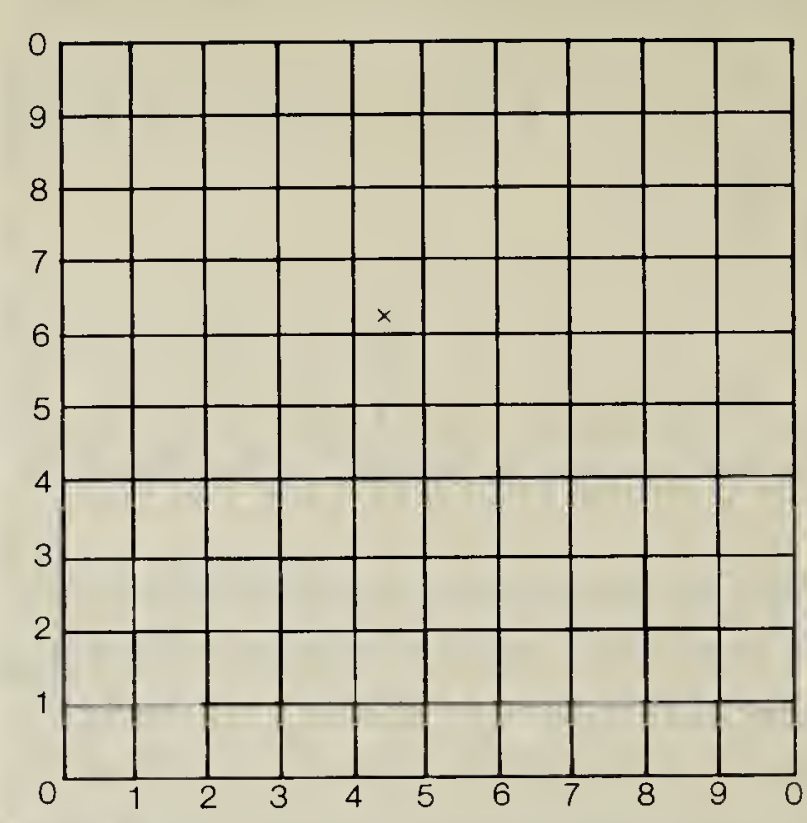

\section{One thousand m universal transverse mercator grid}

dian topographic and avaiation maps published by Energy, Mines and Resources Canada, for the prairie region at least, began appearing with U.T.M. grid overprints so we, also, could promote its use. Furthermore, we should be advocating establishment of a central data bank for storage of collection data in Canada.

Topographic maps published by Energy, Mines and Resources Canada at a scale 1:250,000 are overprinted with a $10 \mathrm{~km}$ grid and marginal designations in blue; those scaled 1:50,000 with a 1 $\mathrm{km}$ grid and marginal designations, also in blue. The 1:50,000 maps on either side of U.T.M. zone boundaries additionally show marginal designations for immediately adjacent U.T.M. zones. These are printed in brown but lack brown grid overprintings.

For further information, and instructions how to use the U.T.M. systems, refer to a booklet published by the Queen's
Printer, Ottawa, 1969, and prepared by staff members of Energy, Mines and Resources Canada, Surveys and Mapping Branch, Ottawa. This booklet entitled "The Universal Transverse Mercator Grid, as Applied to National Topographic System Maps of Canada", (13 pages), describes the appropriate procedures for using the system.

I am indebted to Drs. Owen Olfert and Peter Mason of the Agriculture Canada Research Station, Saskatoon, for constructive criticisms during preparation of this paper.

EDITOR'S NOTE: The Forestry Division of Saskatchewan Parks and Renewable Resources has been using the U.T.M. grid for several years now for the Forest Inventory Mapping System. Maps at scales of 1:12,500 and photographic reductions to $1: 25.000$ have been completed for about $90,000 \mathrm{~km}^{2}$ in the Provincial Forest. 